\title{
Climate change impact and adaptation for highway asphalt pavements: a literature review
}

\author{
Surya T. Swarna and Kamal Hossain
}

\begin{abstract}
For the past few decades, researchers all over the world have agreed that the service life of civil infrastructure is significantly affected by climate change. Pavement is one of these significant infrastructures that can be easily affected by climate change. However, it is well known that predicting climate change is highly complex and dynamic. Hence, a review has been done on available climate change models and the uncertainties involved in climate change prediction. This review addresses various important questions, such as (i) what climate change is, (ii) how to use climate change models, (iii) uncertainties involved in using climate change models, $(i v)$ how climate change impacts pavement infrastructure, $(v)$ the adaptation and mitigation strategies available, and (vi) how economic costs and emissions change due to climate change. This review is useful to understand climate change and its implications on pavement infrastructure.
\end{abstract}

Key words: climate change, pavement performance, pavement maintenance, pavement service life, life cycle cost analysis, temperature rise.

Résumé : Au cours des dernières décennies, des chercheurs du monde entier ont convenu que la durée de vie utile des infrastructures civiles est touchée de façon importante par le changement climatique. La chaussée fait partie de ces infrastructures importantes qui peut facilement être affectée par le changement climatique. Cependant, il est bien connu que la prévision du changement climatique est très complexe et dynamique. Par conséquent, on a procédé à un examen des modèles disponibles sur le changement climatique ainsi que des incertitudes associées aux prévisions relatives au changement climatique. Cet examen porte sur diverses questions importantes comme (i) Qu'est-ce que le changement climatique? (ii) Comment utiliser les modèles de changement climatique? (iii) Incertitudes liées à l'utilisation de modèles de changement climatique. (iv) Comment le changement climatique influe-t-il sur l'infrastructure de la chaussée? (v) Quelles sont les stratégies d'adaptation et d'atténuation disponibles? (vi) Comment les coûts économiques et les émissions changent-ils en raison du changement climatique? Cet examen est utile pour comprendre le changement climatique et ses répercussions sur la structure de chaussée. [Traduit par la Rédaction]

Mots-clés : changement climatique, tenue de la chaussée, entretien de la chaussés, durée de vie utile de la chaussée, analyse des coûts du cycle de vie, augmentation de la température.

\section{Introduction}

\subsection{Climate change and its impact}

The last three decades have been riveting for scientists working on climate change. Monitoring, predicting, and communicating changes in weather patterns and their effects on human life has been a talking point amongst scientists, industrialists, and policymakers alike (IPCC 2007). The changing environmental conditions have affected humans in a myriad of ways, directly and indirectly. It has become imperative to make changes in government policies and personal lifestyles to combat the adverse effects of changing environmental conditions. An action plan on climate change has become one of the key agendas of political parties in recent national elections. Fueled by protests, awareness campaigns, and a sense of sustainable living, the consensus on this global issue has garnered enough attention that decisions on crucial activities in almost every sphere are being influenced, keeping their impact on the climate in mind. Transportation infrastructure is one of the sectors looking to adapt to the projections of the changing climate. In the past decade, a number of researchers have looked for ways to tweak pavement parameters to better combat the fluctuating climate conditions.

Temperature, precipitation, incoming percent of sunshine, humidity, wind speed, and groundwater levels are the climate factors that alter pavement performance, design, and service life (Knott et al. 2019a). In addition, other factors, such as permafrost thaw, freezing index, and freeze and thaw cycles, significantly influence the flexible pavement in the Northern part of Canada (Maadani et al. 2021). An undesirable stress on these pavement parameters due to changes in the environmental variables leads to an increased cost for repairs and maintenance. Reviews on the impact of climate change on pavement performance have emphasized a change in design methodology in response to increasing costs. While some studies suggest implementing proactive measures, like increasing thickness (Knott et al. 2020) and upgrading Superpave binder grades (Fletcher et al. 2016), others have recommended early triggered

Received 23 April 2021. Accepted 6 January 2022.

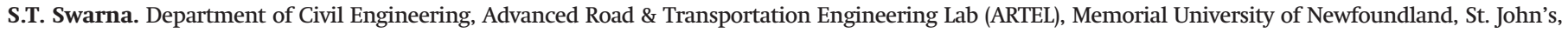
NL A1B 3X5, Canada.

K. Hossain. Department of Civil and Environmental Engineering, Advanced Road \& Transportation Engineering Lab (ARTEL), Carleton University, Ottawa, ON K1S 5B6, Canada.

Corresponding author: Surya Swarna (email: stswarna@mun.ca).

(C) 2022 The Author(s). Permission for reuse (free in most cases) can be obtained from copyright.com. 
maintenance (Qiao et al. 2015). Each of these comes with elevated costs attached. In summary, change in environmental factors due to climate change is known to affect pavement infrastructure and reduce its service life. To maintain the design service life, various adaptation strategies are required, and consequently, costs will escalate.

\subsubsection{Climate change models}

Climate models are the most critical tool for understanding previous climate states and making predictions about the future. They account for natural and human-induced forcing on the climate system and simulate environmental conditions on a range of seasonal to decadal time scales (Meinshausen et al. 2011). Physical laws governing the interactions between atmosphere, ocean, land, and sea ice are expressed in mathematical terms. These expressions of the Earth's systems are converted into computer languages, and parametrizations are then applied to build conceptual models (Flato et al. 2013). Models can be of varying complexities; the most complex ones require substantial supercomputing power. Atmosphere-ocean general circulation models (AOGCMs) consider atmosphere, ocean, land, and sea ice in their parameterizations. Earth system models (ESMs) are the most complex state-of-the-art models currently available. They build upon AOGCMs by including biogeochemical cycles, carbon cycles, sulphur cycles, and ozone (Taylor et al. 2012).

Regional climate models (RCMs) focus on a particular area (for example, North America) to simulate processes pertaining to the continent. Since climate models take a range of natural and anthropogenic parameters as inputs, with assumptions about future scenarios, they are prone to uncertainty (Flato et al. 2013). This, coupled with a lack of efficient computing technologies, leads to approximations, further aggravating uncertainties. To minimize these uncertainties, climate models are often used in a collection of distinct models. The World Climate Research Programme (WCRP), the working group responsible for modelling for the Intergovernmental Panel on Climate Change (IPCC), uses the Coupled Model Intercomparison Project (CMIP) in their assessment reports. These intercomparisons deal with a large group of models from various modelling centers around the world, exploring the range of model behaviors and assessing the strengths and weaknesses of each through controlled experiments. These experiments help to capture errors that are specific to an individual model or that might require a universal theoretical adjustment. Experiments look at "long-term" trends on a 100 year time scale and "near-term" trends on a temporal scale of 10-30 years (Taylor et al. 2012).

The latest report released by IPCC uses the fifth phase of CMIP, CMIP5, which is an ensemble of 55 distinct climate models. A notable development in the prediction methodology of the CMIP5 project is the categorization of future scenarios in terms of radiative forcings (Stocker et al. 2013). Known as the representative concentration pathways (RCPs), this concept defines four predicted greenhouse gas emission scenarios based on social and political aspects of the implementation of mitigation strategies. The RCP 2.6 criteria is the most optimistic, and assumes that the global annual greenhouse gas (GHG) emissions will see a peak between 2010 and 2020, after which the emissions will decline. In RCP 4.5, emissions would peak around 2040 and then decline. RCP 6.0 has a peak around 2080 and decline thereafter. On the pessimistic end, RCP 8.5 sees emissions continuing to rise until the end of the 21st century (Stocker et al. 2013).

\subsubsection{Uncertainties in climate change models}

Natural processes are chaotic, and the effects of such processes generate some of the most intricate patterns in the Earth's environment. Evaluating and then interpreting such systems is a scientific challenge. If the effects of chaotic natural processes are climate systems, then evaluating them using climate models gives rise to uncertainties. Hence, the uncertainties in a climate system form the bulk of problems in a climate model. This section gives a brief investigation into the challenges that uncertainties pose in climate modelling and how scientists work to solve them.

Uncertainties in climate models arise from estimations that define initial conditions, calculated parameters - such as radiative forcing and future population projections - the equations binding them, and the model's design itself (Benjamin and Budescu 2018). As Benjamin and Budescu revealed in their surveys, uncertainties play a massive role in how people perceive climate model results. The authors assessed test subjects' perceptions through their review of two different types of model outputs: one that used precise data but gave conflicting results and another that had imprecise inputs but gave complimentary results. They found that the public was more concerned about the consistency of results rather than the model itself and the physics behind it. Specifically, they had more confidence in imprecise but agreeing models than precise but conflicting ones, as these were prone to misinterpretation. Kudo et al. (2017) investigated how uncertainties from climate models impacted snow models. In their projections of snow processes in Japan, the uncertainties amplified when they were coupled with derivatives from the global circulation model (GCM) results. This resulted in a hugely uncertain prediction of the impact of climate change on snow processes. In a similar study by Kundzewicz et al. (2018), GCM projections were used to run hydrological models to predict future events. The authors mention that selecting an ensemble of several climate models, downscaling techniques to produce RCMs, and scaling mismatch between RCMs and hydrological models are some sources of uncertainty. If these are corrected before running climate impact models, better estimations can be made.

Mauritzen et al. (2017) proposed a way to reduce uncertainties by considering climate sensitivity, which is defined as "a measure of how fast Earth responds to changes in atmospheric carbon dioxide $\left(\mathrm{CO}_{2}\right)$ concentration". Their results emphasize that certain variables in the models have high sensitivity to $\mathrm{CO}_{2}$ emissions and others have low sensitivity. Their analysis demonstrated that subsetting model runs based on sensitivities gave lower uncertainties than full set runs. In another research project, Wang et al. (2019) proposed a new method of handling uncertainties based on hierarchical Bayesian models (BHMs), which only require one simulation run of a model. According to them, traditional methods using ensemble model runs are computationally expensive. Although BHM cannot provide the range of metrics traditional methods provide, some standard diagnostics can be extracted with comparatively less computational power and faster processing speed, while better managing uncertainties.

\subsubsection{Downscaling}

GCMs cannot always be used in their crude form for climateimpact studies because of their resolution. Research in hydrology, transportation, agriculture crop modelling, etc., that involve small-scale estimations are hampered by the low-resolution GCM outputs. Although the scientific community has come a long way in producing finer resolution models since the advent of climate modelling (owing to increased computing power), they are still not good for some local- and regional-scale applications. Presently, GCMs produce outputs at horizontal resolutions of roughly between $1^{\circ}-2^{\circ}$ latitude for atmospheric processes, that is, $\approx 100-$ $200 \mathrm{~km}$ (Flato et al. 2013). It is worth noting that some models can produce a finer resolution of $0.5^{\circ}$ for near-term model runs. On the other hand, RCMs are capable of running at 50-25 km resolutions. Very few models also run at $10 \mathrm{~km}$ resolution (Flato et al. 2013). Climate-impact-related studies often use finer resolutions to match the scale of their study site. Applications to transportation and pavement engineering require environment variables 
Fig. 1. Steps involved in developing a statistical downscaling model (Qiao et al. 2020b). [Colour online.]

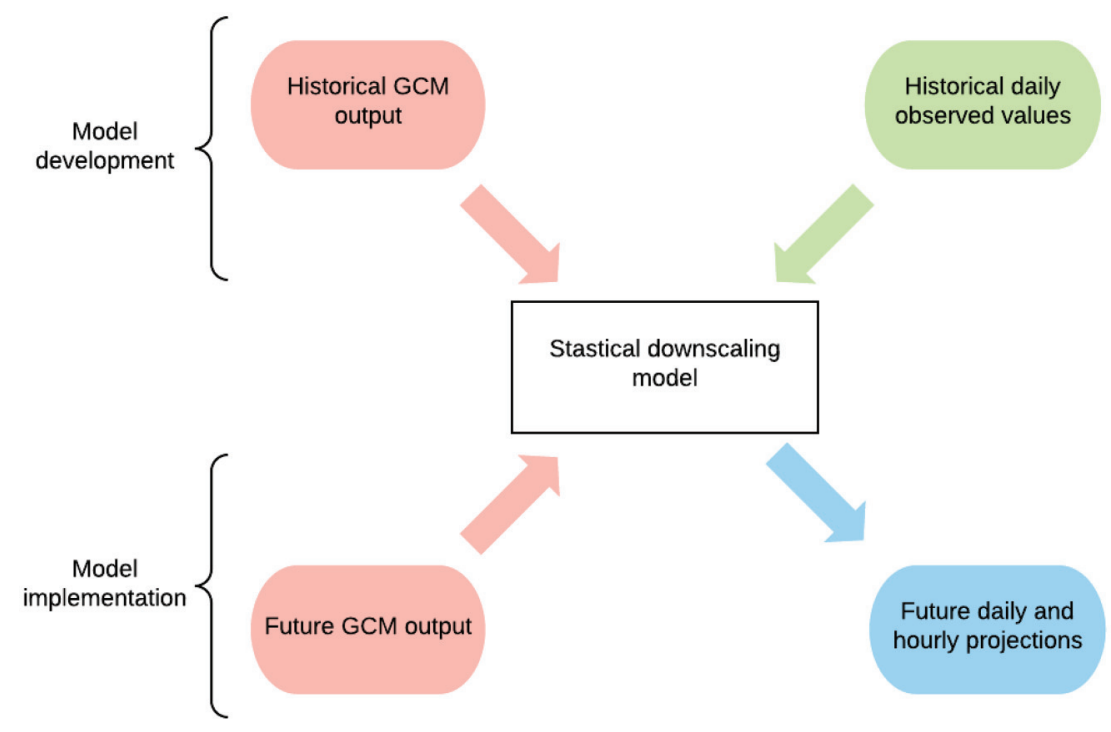

to be resolved to the scale of tens of kilometers spatially, and every hour in a day temporally.

Several downscaling techniques exist, ranging in mathematical complexity and ease of use. The simplest ones involve modifying parameters by a constant value, for example, increasing the mean temperature by $2{ }^{\circ} \mathrm{C}$. Some sophisticated techniques require nesting a high-resolution RCM into GCM outputs. This approach is known as "dynamical downscaling". A moderately complex approach, termed "statistical downscaling", is based on developing a statistical model built on historic data, which is then employed to resolve the coarse GCM future projection data (Qiao et al. 2020a, 2020b). A sketch of the steps involved is exhibited in Fig. 1.

A review of different downscaling techniques by Camici et al. (2014) demonstrates that downscaling can be a significant source of uncertainty. Hence, it is essential to choose an appropriate technique suitable for a particular application. The authors suggest the use of multiple GCMs in such studies. Substantial research has been done to evaluate the efficiency of dynamical and statistical downscaling procedures suitable for different areas of study. Although both have their own strengths and weaknesses and produce similar results of the present climate, they deviate significantly in their future projections (Wood et al. 2004). The dynamical approach is more consistent physically as it uses complex RCM and GCMs. However, nesting the models can magnify the uncertainties of their outputs (Finnis and Daraio 2018). The statistical approach, on the other hand, heavily relies on the current and historical weather values as initial inputs (Finnis and Daraio 2018). The reliance on initial inputs can be a problem in regions where the distribution of weather stations is scarce. However, it has proven to be less complex and computationally less expensive (Murphy 1999).

From the extensive literature review of recent years, it was found that most studies in the civil engineering sector use a statistical downscaling approach. This can be attributed to the fact that statistical downscaling is less complex and requires lower computational power than the nesting method (Valle et al. 2017, Qiao et al. 2020b, Stoner et al. 2019). Dynamical downscaling requires an understanding of complex physical theories and modelling construction to accurately perform the nesting of models. In contrast, with current climate data readily available, relatively simpler statistical downscaling techniques do not impede expertise in modelling.

\subsubsection{Hourly data estimation}

AASHTOware mechanistic-empirical pavement design (MEPD) software, also called mechanistic-empirical pavement design guide (MEPDG) software, is a robust pavement design system used to design both asphalt concrete (AC) and Portland cement concrete (PCC) pavements. This software considers four inputs: material properties for all the layers, traffic volume and distribution, climate, and structural design. The climate inputs in AASHTOware software are hourly air temperature, wind speed, percent sunshine, precipitation, and relative humidity. Most of the studies used AASHTOware to compute pavement performance and service life (ARA Inc. 2004). The MEPDG is bolstered with the enhanced integrated climate model (EICM) to determine the pavement layer system's temperature and moisture distribution (Zapata et al. 2007). Therefore, AASHTOWare MEPD uses hourly decomposed values of temperature, precipitation, percent sunshine, wind speed, and humidity as climate inputs to predict pavement performance. However, due to computational constraints, most climate change models only produce daily maximum and minimum air temperature, and average precipitation estimates of future climate in a changing climate scenario. Hence, it becomes imperative to convert daily climate model data to hourly values. Various algorithms for transforming the predicted climate data have been employed by researchers in the past. Some techniques used in the most recent studies are detailed below.

1.1.4.1. Chartered Institution of Building Services Engineers (CIBSE) method

The Chartered Institution of Building Services Engineers (CIBSE) guide method (Chow and Levermore 2007) fits daily maximum and minimum temperatures using sinusoidal curves at assigned times of occurrence of those temperatures in a day. The maximum and minimum temperature times are suggestions given by CIBSE Guide J and are constant for each month of the year. For example, the maximum temperature for a day in the month of January is assumed to occur at $\mathbf{1 4 0 0}$ hours and minimum temperature at 0600 hours. Mathematically, hourly temperatures are calculated using

$$
T(t)=f_{1} T_{\mathrm{MIN}}+f_{2} T_{\mathrm{MAX}}
$$

where $T_{\text {MAX }}$ is the maximum temperature occurring at time $t_{\max }$, $\mathrm{T}_{\mathrm{MIN}}$ is the minimum temperature occurring at time $t_{\mathrm{min}}$, and $f_{1}$ 
Fig. 2. Sinusoidal interpolation of daily temperature values.

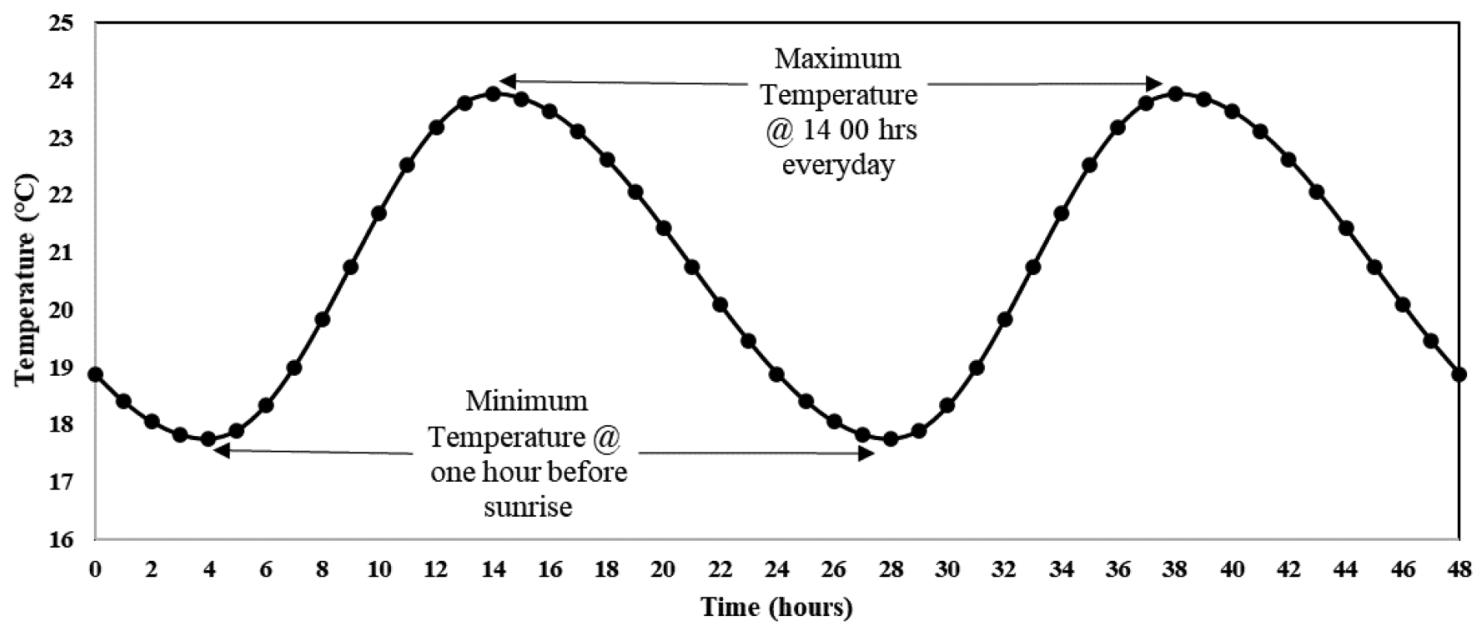

and $f_{2}$ are factors of sinusoidal interpolation, where $f_{1}+f_{2}=1$, given by:

For $t<t_{\min }$

$$
f_{1}=\frac{1}{2}\left\{\cos \left[\frac{\pi\left(t_{\min }-t\right)}{24}+t_{\min }-t_{\max }\right]+1\right\}
$$

For $t_{\min }<t<t_{\max }$

$$
f_{1}=\frac{1}{2}\left\{\cos \left[\pi\left(t-t_{\min }\right)+t_{\min }-t_{\max }\right]+1\right\}
$$

For $t_{\min }<t$

$$
f_{1}=\frac{1}{2}\left\{\cos \left[\frac{\pi\left(24+t_{\min }-t\right)}{24}+t_{\min }-t_{\max }\right]+1\right\}
$$

\subsubsection{2. $\sin (14 \mathrm{R}-1)$ method}

This method also employs a sine curve fit to daily extremes, but the difference lies in the assumption of times of occurrence for these values (Chow and Levermore 2007). In contrast to the CIBSE method of assigning constant times for any day in a month, the sin $(14 R-1)$ method takes into account the intensity of the incoming percent sunshine to define times of occurrence for extreme temperatures in a day. Knowing the latitude of the study location and the day of the year, sunrise time is first calculated using standard relations. The time of minimum temperature, $t_{\mathrm{min}}$, is then taken as the hour before sunrise, whereas the time of maximum temperature, $t_{\max }$, is assumed constant at 1400 hours, regardless of the time of the year. The sinusoidal curve is then fit, and hourly values are extracted similar to the CIBSE method. A very similar technique, called the $\sin (14 \mathrm{R})$ method, takes the time of occurrence for the minimum temperature to be the time of sunrise instead of the hour prior. The maximum temperature time is still taken at 1400 hours, as illustrated in Fig. 2. Valle et al. (2017) demonstrated the utility of this modified technique in their assessment of pavement in a changing climate condition.

The above algorithms generate hourly temperatures for a single day. To calculate parameters for a number of consecutive days, a sinusoidal curve can be stretched to link a day's minimum with the immediate maximum of the next day. Knowing extreme temperatures and the times of their occurrence, hourly temperatures for each day can be extracted using
(5) $\quad T(t)=\frac{T_{(\text {next })}+T_{(\text {prev })}}{2}$

$$
-\left[\frac{T_{(\text {next })}-T_{(\text {prev })}}{2} \cos \left(\frac{\pi\left(t-t_{(\text {prev })}\right)}{t_{(\text {next })}-t_{(\text {prev })}}\right)\right]
$$

where $T_{\text {(next) }}$ is the successive known temperature at time $t_{\text {(next), }}$ and $T_{(\text {prev })}$ is the previous temperature at time $t_{(\text {prev) }}$.

1.1.4.3. Quarter-sine (Q-sin) method

This method, developed by Chow and Levermore, is an adaptation of the $\sin (14 R-1)$ method (Chow and Levermore 2007). The Q-sin technique aims to achieve better accuracy in predicting hourly temperatures by including daily average temperature in its calculations in addition to daily extreme temperature data as in the previous algorithms. Consequently, a quarter sinusoidal curve is fitted with three points.

The Q-sin method also assigns the extreme occurrence times similar to the $\sin (14 R-1)$ method. If the first point fits with $T_{\text {MIN }}$ and $T_{\text {MAX }}$ as endpoints. Then, $T_{\text {ave }}$ is estimated from this $\mathrm{Q}$-sin curve and matched with the value acquired from the model outputs, as presented in Fig. 3. Any difference in the values is accounted for with an adjustment in the curve fit. This process is devised to be a robust mechanism to minimize curve fitting errors by considering three points to fit an approximate curve. A quarter-sine curve is thus fit with $T_{\text {ave }}$ as an interior point, and the time of its occurrence, $\lambda$, is derived. The difference between the two sine curves is used to eventually extract hourly temperature for a range of days. The equations involved are

$$
\begin{aligned}
24 D= & \left(\frac{T_{\mathrm{MAX}}-\mathrm{T}_{\mathrm{MIN}}}{2}\right)\left(\lambda-t_{\mathrm{min}}\right)\left(1-\frac{2}{\pi}\right) \\
& +\left(\frac{\mathrm{T}_{\mathrm{MAX}}-\mathrm{T}_{\mathrm{MIN}}}{2}\right)\left(t_{\mathrm{max}}-\lambda\right)\left(1+\frac{2}{\pi}\right) \\
& -\left(\frac{\mathrm{T}_{\mathrm{MAX}}-\mathrm{T}_{\mathrm{MIN}}}{2}\right)\left(t_{\mathrm{max}}-t_{\mathrm{min}}\right) \\
\lambda= & \frac{\left(t_{\mathrm{max}}-t_{\mathrm{min}}\right)}{2}-\left(\frac{12 D_{2} \pi}{T_{\mathrm{MAX}}-\mathrm{T}_{\mathrm{MIN}}}\right)
\end{aligned}
$$

where $T_{\text {MAX }}$ is the maximum temperature occurring at time $t_{\max }$, and $\mathrm{T}_{\mathrm{MIN}}$ is the minimum temperature occurring at time $t_{\mathrm{min}}$. 
Fig. 3. Sinusoidal curve fit using Q-sin method, (a) quarter sine curve $t$ in the region $\lambda>t_{\min }$ and $(b)$ quarter sine curve $t$ in the region $\lambda<t_{\max }$ [Colour online.]

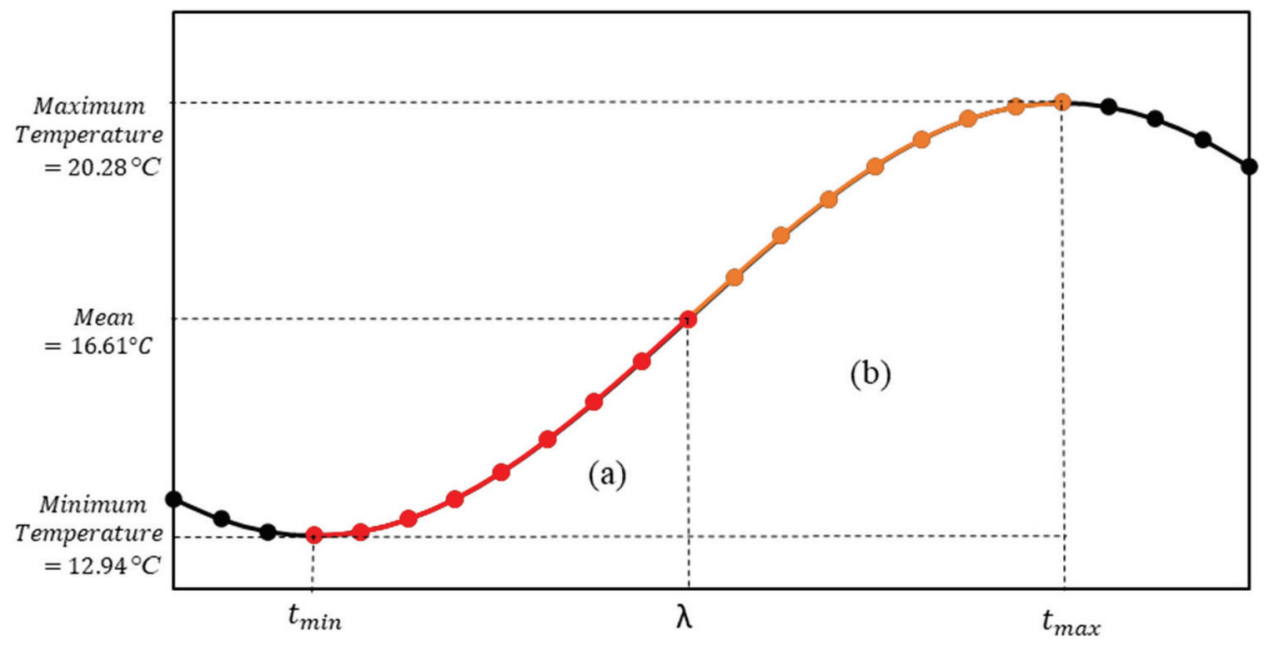

\subsubsection{Imposed offset morphing method (IOMM)}

The imposed offset morphing method (IOMM) is based on reconstructing a past weather pattern to predict future daily climate variables with a finer temporal resolution and was used by Gudipudi et al. (2017) and many others (Belcher et al. 2005). In principle, historic daily minimum and maximum temperature data are first acquired from climate model outputs, along with future projections of the daily extremes for equal ranges of years. Then, by applying a sequence of "shifting", "stretching", or a combination of both, to the data, hourly values for a future period of time are obtained using historic hourly temperature distribution,

$$
T_{\mathrm{iF}}=\frac{T_{\mathrm{FMax}}-T_{\mathrm{FMin}}}{T_{\mathrm{BMax}}-T_{\mathrm{BMin}}}\left(T_{\mathrm{iB}}-T_{\mathrm{BMin}}\right)+T_{\mathrm{FMin}}
$$

where $T_{B M i n}$ and $T_{B M a x}$ are the daily minimum and maximum temperatures extracted from the historic climate database, $T_{\mathrm{FMin}}$ and $T_{\text {Fmax }}$ are the daily minimum and maximum temperatures extracted from the given projected climate data (climate change model), and $T_{\mathrm{iB}}$ is the hourly distribution of historic temperature.

Similarly, using the historical hourly precipitation data, the future hourly precipitation data can be estimated from the daily average precipitation extracted from the climate change model. The following equation is used to compute the hourly precipitation data for the future climate:

$$
R_{\mathrm{iF}}=\left[\frac{\left(R_{\mathrm{FMAvg}}-R_{\mathrm{BMAvg}}\right)}{R_{\mathrm{BMAvg}}} R_{\mathrm{iB}}\right]+R_{\mathrm{iB}}
$$

where cumulative monthly rainfall for the baseline case was extracted and used to calculate an average daily precipitation rate for the respective month, $R_{\mathrm{BMAvg}}$ is the average daily precipitation of each month extracted from the historic climate data base, $R_{\mathrm{FMAvg}}$ is the average daily precipitation of each month extracted from the given climate projection (climate change model), and $R_{\mathrm{iB}}$ is the hourly rainfall for historical climate data.

\section{Methodology of literature review}

In undertaking the literature review on this topic, multiple resources were used. In addition, four phases were carried out in gathering, reviewing, and filtering this literature. In the first phase, various databases such as Google Scholar and ResearchGate were utilized to extract most of the literature on the "impact of climate change on pavement infrastructure". The keywords were extracted from the articles gathered from Google Scholar and
ResearchGate that refer to this particular topic. In the second phase, various keywords related to this topic were used to search for literature on ASCE, IJPE, RMPD, TRB, TRR, and other transportationrelated journal databases. In the third phase, we reviewed the abstract, introduction, and conclusions and sorted the articles according to subtopics. All the articles were examined and sorted by relevance to this particular topic in the final phase. In this sorting process, we selected 98 out of 220 articles gathered from various sources. The literature review of the selected articles is presented in this paper.

\section{Pavement materials perspective}

Other than traffic loads, climate factors, such as temperature, precipitation, and percent sunshine, are the primary cause of pavement material degradation. These changes in temperature and precipitation mean pavement materials are deteriorating earlier than expected, leading to the failure of the pavement structure. Upgrading the Superpave binder grade according to the temperature rise may reduce the pavement deterioration and result in a longer service life (Mills et al. 2009; Qiao et al. 2013a; Viola and Celauro 2015; Underwood et al. 2017).

\subsection{Superpave binder grade selection}

Several studies noticed a temperature rise due to climate change in Canada (Vincent et al. 2018), the United States (Paquin et al. 2014), South America (Marengo et al. 2012), Europe (Meleux et al. 2007), Africa (Jones and Thornton 2009), the Middle East (Evans 2009), China (Zhai and Pan 2003), India (Dash et al. 2007), Central Asia (Lioubimtseva and Henebry 2009), Southeast Asia (Gasparrini et al. 2017), and Australia (Hughes 2003). To account for this temperature rise, Mills et al. (2009) estimated the change in Superpave binder grade for 17 sites in southern Canada, which revealed that low-temperature cracking would not be problematic in future years. It was also noticed that six out of 17 sites needed an upgrade to high-temperature grade, and at eight out of 17 sites, there was a rise in low-temperature grade (Mills et al. 2009). Similar work was done by Viola and Celauro (2015) in Italy to evaluate the asphalt binder upgrade at 71 different locations. In this study, 2013 was considered as the baseline and upgrades in asphalt binder grades were estimated for 2033. It was noted that there was an increase of one grade in high-temperature grade over $27 \%$ of the Italian territory. On the other hand, there was no noticeable change in low-temperature grades in this territory (Viola and Celauro 2015). A similar study was carried out for the binder selection in Chile (Delgadillo et al. 2020). A total of 94 weather stations were considered in the selection of 
asphalt binder grades throughout the country. This study identified a significant number of stations in need of a change in binder grade. Fletcher et al. (2016) estimated the change in pavement temperature for the selected Superpave asphalt binder grade for the future climate in Canada. They concluded that nine out of 17 cities exhibited an increase in asphalt binder grade. In a similar study, Shafiee et al. (2020) determined the influence of climate change on short-, medium-, and long-term future performance-graded asphalt cement (PGAC) selection. This study concluded that the examined sites may need a significant upgrade in PGAC depending on climate change model and corresponding RCP scenario. Another study, which is specific to the province of Ontario, also concluded a significant change in PGAC over all the examined cities in Ontario (Basit et al. 2021).

In very recent years, a study was carried out to assess the upgrade of asphalt binder grade in the United States. The study noticed that, over the 799 observed weather stations, 35\% of the stations' asphalt binder grades based on 1965-1996 are different from the binder grades based on 1985-2014 weather data (Underwood et al. 2017). This study also estimated the expected number of increments in high temperature grade due to climate change for different RCP's and different periods, which concluded that the examined scenarios projected a maximum of a two-grade change for the future climate in the United States.

All of these studies used different climate change models and different methods for the estimation of pavement temperature from air temperature. Also, all the studies are spatiotemporally variable. However, the mutual conclusion of all of the studies is that the climate is becoming warmer, which requires adaptation by upgrading the asphalt binder grade.

\subsection{Effect on surface HMA layer}

Mallick et al. (2014) discerned the impact of climate change on surface hot mix asphalt (HMA) layer modulus, which tends to reduce due to temperature rise. Also, this study evaluated the adjusted modulus for the effect of water through inundation (flooding). However, Mallick et al. (2014) concluded that the inundation period was not significant. Therefore, the number of inundation cycles is assumed to have an influence on HMA modulus. In another similar study, it was noted that the temperature rise due to climate change results in the reduction of stiffness properties of HMA layer (Mallick et al. 2016), which leads to an increase in pavement deformation.

Kumlai et al. (2017) studied the impact of increased temperature due to climate change on western Australian asphalt mixes. This study estimated the effective dynamic modulus $\left(\left|E^{*}\right|_{\text {eff }}\right)$ for the increased effective pavement temperature. The results of this study revealed that the increase in effective temperature causes a significant reduction in the effective dynamic modulus, which tends to decrease the service life of the pavement.

Shao et al. (2017) described the indirect impact of climate change on pavement materials and stated that the increase in temperature accelerates the aging of asphalt cement, resulting in an increase in brittle failure (cracking) of the surface layer. Further, this brittle failure allows surface water to enter pavement layers and causes potholes and loss of surface material. Qiao et al. (2016) also noticed a similar effect: an increase in precipitation causes ravelling and stripping of asphalt mix at the initial stage. Then, this stripping and ravelling allow surface water to infiltrate into the asphalt mixture, which affects the bonding between the asphalt binder and aggregate. Furthermore, the surface water infiltration leads to severe damage (potholes) to the pavements. This surface water infiltration may cause delamination if water enters between the two HMA layers (Swarna and Hossain 2018).

\subsection{Effect on granular materials and subgrade layers}

Qiao et al. (2016) noticed that the increase in precipitation is expected to increase the moisture content in unbound granular layers, leading to an increase in permanent deformation. However, an increase in precipitation will lead to having greater runoff and is likely to result in small or negative net infiltration to the subgrade. Also, the warmer temperatures are expected to dry the aggregates sooner (Bizjak et al. 2014). Bizjak et al. (2014) concluded that uncracked pavement surfaces could handle the increase in precipitation. Nevertheless, extreme precipitation events are key challenges for upgrading the drainage provision.

Mallick et al. (2017) estimated the duration of flooding needed to cause complete saturation of base layers ( $\left.T_{\text {critical }}\right)$. In addition, the effect of pavement design factors on $T_{\text {critical }}$ is also determined. This study found that the type of HMA gradation, voids in surface HMA layer, and thickness of surface HMA layer significantly impact $T_{\text {critical }}$. It was also found that the thickness of base layer has a moderate effect on $\mathrm{T}_{\text {critical }}$. In this study, Mallick et al. (2017) developed a simulation tool to determine $T_{\text {critical }}$, which is useful to determine the pavement's post-flood condition. In a similar study, Asadi et al. (2020) developed a computational algorithm to quantify life loss due to flooding and heavy rainfall. The postflooding structural response was determined based on 10 different factors: gradation variables (D60, D10, and P200) of the base material, weighted plasticity (wPI) of subgrade material, initial saturation of the base and subgrade, thickness of the base and HMA, infiltration rate, and infiltration time. Also, using the post-flood structural responses, loss of pavement life due to flooding was computed.

Mallick et al. (2014) evaluated the impact of average annual rainfall over the pavement structure and noticed that the increase in the number of inundations over time would result in the reduction of effective subgrade modulus, which will lead to an increase in permanent deformation. In this study, the inundations are considered not only due to an increase in rainfall but also due to the increase in the number of category 3 hurricanes. In continuation, another study noted that stabilized subgrades could enhance the pavement performance (Mallick et al. 2016). Strengthening the base layers of flexible pavement is another adaptation approach to counteract the increase in precipitation (Melvin et al. 2016).

It has to be noted that the EICM associated with MEPD assumes that the pavement is designed with a sufficient drainage system to drain the water infiltration. In other terms, the MEPD does not account for the water infiltration during flooding and inundation. Therefore, it is not appropriate to use MEPD to determine the influence of extreme events such as flooding and inundation on a pavement system (Achebe et al. 2021).

\section{Performance and design perspective}

Many studies assess the impact of climate change on pavement performance using climate change models in various parts of the world, as presented in Table 1 , which highlights that climate change predominantly causes permanent deformation and fatigue cracking. It is also evident that all of the studies considered temperature rise to assess the impact on pavement performance. Few studies considered all the climate factors to estimate the impact on pavement performance. In this review article, the climate factors considered are temperature, precipitation, wind speed, percent sunshine or solar sunshine, humidity, and groundwater table. Additionally, the pavement performance parameters considered are total rutting, asphalt concrete (AC) rutting, top-down (TD) cracking, bottom-up (BU) cracking, thermal or traverse cracking, and international roughness index (IRI).

\subsection{Pavement performance}

\subsubsection{Surface distresses}

The impacts of climate change on Canadian flexible pavements were investigated by the University of Waterloo for a period of 20 years starting from 2050 using two climate change models, Coupled Global Climate Model 2 (CGCM2A2x) and Hadley Climate 
Table 1. Impact of climate change on pavement performance reported in various studies.

\begin{tabular}{|c|c|c|c|c|c|c|c|c|c|c|c|c|c|c|}
\hline \multirow[b]{2}{*}{ Source } & \multirow[b]{2}{*}{$\underset{\mathscr{U}}{\mathscr{U}}$} & \multicolumn{7}{|c|}{ Climate factor considered } & \multicolumn{6}{|c|}{ Performance parameter } \\
\hline & & 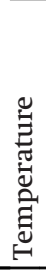 & 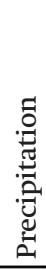 & 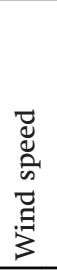 & 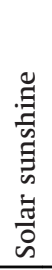 & 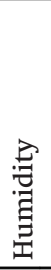 & 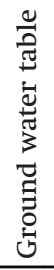 & 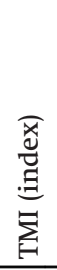 & 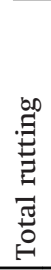 & 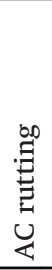 & 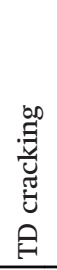 & 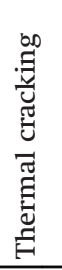 & 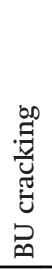 & 必 \\
\hline Tighe et al. (2008) & $\checkmark$ & $\checkmark$ & $\checkmark$ & & & & & & $\uparrow$ & $\uparrow$ & $\uparrow$ & $\downarrow$ & $\uparrow$ & $\uparrow \downarrow$ \\
\hline Mills et al. (2009) & $\checkmark$ & $\checkmark$ & $\checkmark$ & & & & & & $\uparrow$ & $\uparrow$ & $\uparrow$ & $\downarrow$ & $\uparrow$ & $\uparrow \downarrow$ \\
\hline Meagher et al. (2012) & & $\checkmark$ & $\checkmark$ & $\checkmark$ & $\checkmark$ & $\checkmark$ & & & $\uparrow$ & $\uparrow$ & & & $\uparrow \downarrow$ & \\
\hline Wistuba and Walther (2013) & & $\checkmark$ & & $\checkmark$ & $\checkmark$ & $\checkmark$ & & & & & & & $\uparrow$ & \\
\hline Bizjak et al. (2014) & & $\checkmark$ & $\checkmark$ & & & & & & $\uparrow$ & $\uparrow$ & $\uparrow$ & $\downarrow$ & $\uparrow$ & $\uparrow \downarrow$ \\
\hline Qiao et al. (2013a) & & $\checkmark$ & $\checkmark$ & $\checkmark$ & $\checkmark$ & & $\checkmark$ & & $\uparrow$ & $\uparrow$ & $\uparrow$ & & $\uparrow$ & $\uparrow$ \\
\hline Qiao et al. (2013b) & & $\checkmark$ & $\checkmark$ & $\checkmark$ & $\checkmark$ & & $\checkmark$ & & $\uparrow$ & $\uparrow$ & $\uparrow$ & & $\uparrow$ & $\uparrow$ \\
\hline Zareie et al. (2016) & $\checkmark$ & & & & & & & $\checkmark$ & & & & & & $\uparrow$ \\
\hline Gudipudi et al. (2017) & & $\sqrt{ }$ & $\checkmark$ & & & & & & $\uparrow$ & $\uparrow$ & $\uparrow$ & & $\uparrow$ & \\
\hline Shao et al. (2017) & & $\sqrt{2}$ & $\checkmark$ & & $\checkmark$ & & & $\checkmark$ & & $\uparrow$ & & & $\uparrow$ & $\uparrow$ \\
\hline Stoner et al. (2019) & & $\checkmark$ & $\checkmark$ & $\checkmark$ & $\checkmark$ & $\checkmark$ & & & $\uparrow$ & $\uparrow$ & $\uparrow$ & & $\uparrow \downarrow$ & $\uparrow \downarrow$ \\
\hline Underwood (2021) & & $\checkmark$ & & & & & & & $\uparrow$ & $\uparrow$ & & & $\uparrow$ & \\
\hline Rana et al. (2020) & $\checkmark$ & $\checkmark$ & $\checkmark$ & & & & & & $\uparrow$ & $\uparrow$ & $\uparrow$ & & $\uparrow$ & $\downarrow$ \\
\hline
\end{tabular}

Note: $\checkmark$, considered in the study; $\uparrow$, increasing compared to the baseline climate; $\downarrow$, decreasing compared to the baseline climate; $\uparrow \downarrow$, increasing and decreasing compared to the baseline climate.

Model 3 (HadCM3B21). This study noticed that the change in temperature, rainfall, and traffic growth are significant factors influencing pavement performance (Tighe et al. 2008; Mills et al. 2009). This study utilized AAHSTOWare ME Pavement Design to quantify the climate change impact on pavement performance. However, as there are no local calibration factors available for the Canadian provinces, the author relied on global calibration factors to estimate the climate change impact on pavement performance, which might not be an accurate prediction. Another study evaluated the consequences of climate change on the pavement deterioration process assessed using the REgional MOdel (REMO), which was downscaled to a $10 \mathrm{~km}$ grid resolution and hourly time scale (Meagher et al. 2012). From this study, it was found that the impact of temperature rise on asphalt concrete permanent deformation is modest and negligible for fatigue cracking. In Europe, time variation curves of climate factors such as air temperature, global radiation, wind speed, and humidity are predicted to estimate these factors' effects on future pavement design. Surprisingly, in central Europe, the impact of climate change was judged as negligible. Also, for Germany and Austria, adaptation strategies as a consequence of climate change were not a necessity (Wistuba and Walther 2013). In freezing zones, road transport relies on the frozen road during the winter season; however, temperature rise in the northern regions will result in a shorter frozen period. In this kind of case, necessary upgrading of thin and unsealed pavements is necessary to provide reliable bearing capacity for the roads throughout winter (Bizjak et al. 2014). This research also determined the impact of an increase in temperature and precipitation individually on all the pavement distresses in Europe. From this, it was noticed that, due to temperature rise, all the distresses are increasing except thermal cracking. Also, the same trends are observed for the increase in precipitation cases (Bizjak et al. 2014).

The influence of climate factors such as temperature, precipitation, wind speed, percent sunshine, and groundwater table on pavement performance was assessed by Qiao et al. (2013a, 2013b). Climate change models are only available for temperature and precipitation, which were produced from MAGICC (Model for the Assessment of Greenhouse-gas Induced Climate Change) and SCENGEN (SCENario GENerator). Therefore, an increase of $5 \%$ was assumed for the other factors to estimate the impact on pavement performance. From this study, it was found that longitudinal cracking is affected by all the climate factors. Also, all the distresses are highly influenced by temperature rise. Pavement performance is investigated using climate data from an assembly of 19 different climate change models from CMIP5 database for five different sites in the United States. Due to an increase in temperature, the percentage of AC rutting was expected to increase by $9 \%-40 \%$ and the percentage of fatigue cracking was also expected to increase by $2 \%-9 \%$. Also, for the considered five sections, there is no considerable difference in the pavement performance due to a change in precipitation (Gudipudi et al. 2017).

A recent study utilized Austroads Climate Tool to forecast climate change. This climate data was processed into proper form as input to HDM-IV to estimate the climate change impact on pavement performance. It was concluded that the increase in temperature is likely to affect the asphalt materials through asphalt aging, embrittlement, and cracking. Furthermore, it was found that rainfall alters moisture imbalance and leads to pavement deterioration (Shao et al. 2017). A very recent study assessed the impact of three climate change models on pavement performance in 24 different locations across the United States. The study exhibits different performance trends for the 24 locations; however, all the results illustrated a decreasing trend for pavement performance under current design standards (Stoner et al. 2019). Also, it was noticed that the AC permanent deformation is mostly affected by the increase in temperature.

To select the appropriate GCM for the pavement performance evaluation, Underwood (2021) verified the detailed pavement performance analyses using various models in four different states. This study illustrated a summary of model selection process based on pavement distress prediction and the type of region. Also, this study noticed that there was an increase in rutting and fatigue cracking for the selected four sites due to an increase in air temperature alone (Underwood 2021).

\subsubsection{Roughness}

A study was carried out to estimate the impact of future temperature, precipitation, and projected traffic on pavement roughness progression in Canada. From this study, it was found that the IRI is increasing in most of the Canadian provinces. Unexpectedly, a decreasing trend was noticed in Quebec and Newfoundland and 
Labrador (Tighe et al. 2008, Mills et al. 2009). The same trend was noticed in recent studies carried out by Rana et al. (2020) and Swarna et al. (2021) in Newfoundland and Labrador. Bizjak et al. (2014) noticed a similar trend in Europe, and estimated the pavement roughness due to increases in temperature and precipitation individually, which revealed the approximate reason for the decreasing trend. The decrease in the IRI is predominantly due to the rise in temperature while an increasing IRI trend was noticed for the rise in precipitation.

Qiao et al. (2013a, 2013b) assessed the impact of all climate factors on the IRI of pavement in Virginia, USA. It was noted that the IRI is not sensitive to the increase in temperature. However, the IRI is slightly affected by the change in precipitation. The interaction effect of future traffic loads and Thornthwaite moisture index (TMI) on pavement deterioration was estimated for three 30 year periods in the 21st century (Zareie et al. 2016). In this study, an increase in TMI can cause an $11 \%-68 \%$ increase in roughness progress rate on pavement structure. In another similar work, Stoner et al. (2019) noted that there was no significant difference in IRI between baseline and climate change. However, Rana et al. (2020) noticed that in the province of Newfoundland and Labrador, Canada, the distresses, such as total rutting, fatigue cracking, and AC rutting, are increasing and the IRI is decreasing, which is unusual. Also, the authors noted that this may be because of the difference between the IRI model for freezing and non-freezing zones in MEPD.

From all the reviewed literature, many contradicting results have arisen; however, all these conflicting results may be because the studies used different climate change models in different locations. So, it is necessary to determine the variables that affect the IRI of pavement.

\subsection{Pavement design and service life}

Qiao et al. (2013b) estimated change in the service life (SL) of the pavement due to climate change and found that there was a minimum of $20 \%$ reduction in pavement service life due to climate change. This service life is computed based on minimum acceptable service quality, defined as follows:

$$
\mathrm{SL}=\min \left(\mathrm{SL}_{1}, \mathrm{SL}_{2}, \mathrm{SL}_{3}, \ldots\right)
$$

where $\mathrm{SL}_{1}, \mathrm{SL}_{2}, \mathrm{SL}_{3}, \ldots$ are the service lives computed for each distress (such as longitudinal cracking, transverse cracking, fatigue cracking, IRI, AC rutting, and total rutting, which were the direct outputs of the MEPDG).

Jeong et al. (2017) assessed the impact of climate change on pavement service life for various climate change scenarios, and found that service life reduces drastically due to climate change. Also, it was noted that the service life for the RCP 2.6 scenario was higher than that of normal climate. However, the service life for the RCP 8.5 scenario was much lower than the RCP 2.6 and normal climate. This indicates that there is a significant reduction in pavement service life due to climate change.

Knott et al. (2019b) estimated the increase in hot mix asphalt (HMA) thickness to preserve the service life of pavement due to warming temperatures. Factors such as seasonal average temperature, change in season length, and temperature-dependent resilient modulus were used to simulate the pavement response due to a rise in temperature. The results indicate that the existing base layers are performing well with $85 \%$ reliability. However, HMA layer thickness needs to be increased by $7 \%-32 \%$ based on the season. Furthermore, Knott et al. (2019a, 2020) extended the study to estimate the necessary increase in HMA and base layer thickness due to groundwater rise. Here, the HMA thicknesses are estimated for 70 combinations of incremental temperature and groundwater rise. The results found that the temperature rise, and groundwater rise will reduce the pavement service life, especially in coastal regions. However, an increase in HMA layer thickness and base layer thickness will result in resilient pavements (Knott et al. 2019a, 2020).

\section{Pavement maintenance and rehabilitation perspective}

It is clearly described in the above sections that pavement deterioration is significantly increased due to climate change. This increase in pavement deterioration entails the necessity of early maintenance and rehabilitation to prevent pavement failure (Mills et al. 2006). Many studies estimated the need for early maintenance and rehabilitation due to climate change.

\subsection{Effect on intervention frequency}

Tighe et al. (2008) estimated change in the timing of maintenance requirements occurring due to both individual and combined influences of climate change and traffic growth in six regions of southern Canada (Tighe et al. 2008, Mills et al. 2009). This study noticed that the number of years to reach $2.7 \mathrm{~m} / \mathrm{km}$ of IRI (maintenance threshold) significantly declined due to climate change and traffic growth in two provinces. However, in Quebec, the number of years to reach the maintenance threshold increased due to climate change alone. Then again, when traffic is considered, the number of years to reach the maintenance threshold dropped. Chai and Kelly (2014) estimated the increase in annual maintenance costs due to climate change in Australia. In this study, annual maintenance cost was expected to increase about $30 \%$ due to climate change conditions by 2060.

Qiao et al. (2013b) also estimated the drastic reduction in the service life of pavement due to climate change. To conserve the pavement service life, pavement should undergo frequent maintenance earlier than expected. In this regard, Qiao et al. (2015) noticed that the pavement maintenance was triggered $8 \%-16 \%$ earlier due to climate change. Another study used Monte Carlo analysis to estimate the percentage of roads that require rehabilitation at 50 and 100 years (Mallick et al. 2016). In this study, various conditions such as no climate change, climate change, and climate change with different adaptation scenarios are evaluated. From this study, it was well noted that the modified HMA and stabilized subgrade would result in a lower percentage of roads needing rehabilitation compared to climate change and no climate change conditions.

Jeong et al. (2017) assessed the impact of climate change on pavement service life for various climate change scenarios. Further, a climate change impact assessment system using fuzzy logic interface was proposed to predict the service life of infrastructure. This method is predominantly developed to minimize the additional expenditure on pavement infrastructure by establishing proactive adaptation (rehabilitation) strategies. This study estimated the condition rating for pavement from 2016 to 2100 for various climate change scenarios. The rehabilitation cycle for RCP 2.6 is 16.5 years, which was much higher than RCP 8.5. Unexpectedly, the rehabilitation cycle for the normal climate was observed to be less than that of RCP 2.6, which might be because of the reduced $\mathrm{CO}_{2}$ concentration level after 2020 for RCP 2.6. However, further analysis is needed to understand the effect of the RCP 2.6 climate change model compared to a normal climate.

Chen and Wang (2020) estimated the impact of warming temperatures on flexible pavement overlay performance. To estimate this impact, a maintenance strategy of milling 3 inches and overlaying 3 inches was adopted when the pavement reaches a performance threshold of $10 \%$ lane area of total fatigue cracking. Similarly, a maintenance strategy of milling 3 inches and overlaying 6 inches was adopted when the pavement reaches a performance threshold of $20 \%$ lane area of total fatigue cracking. After the overlay, performance in terms of IRI, fatigue cracking, and rut depth was monitored due to both normal and warming temperatures. Also, the service life of the overlay is estimated. It was 
concluded that the warming temperatures result in increased fatigue cracking, rutting, IRI, and decreased service life for the pavement overlays (Chen and Wang 2020).

\section{Economics and emissions perspective}

From the above review, it was evident that climate change accelerates pavement deterioration, which leads to the reduced service life of pavements. To uphold the design service life, it is necessary to design and maintain the pavements considering the future climate. This adaptation results in preserving the pavements throughout the design service life, which might increase the life cycle cost of pavements; however, these will be beneficial in the long run. Besides, adapting to climate change might also increase greenhouse gases further in the atmosphere. So, there is a necessity to optimize the adaptation strategies to preserve the service life of pavement with less economic cost and lower emissions generated.

\subsection{Life cycle cost analysis (LCCA)}

Schweikert et al. (2014) estimated the impact of climate change on adaptation and opportunity costs for 10 countries, which were categorized based on income level. These countries are divided into three categories: low-, medium-, and high-income countries. Average annual costs and opportunity costs are estimated for both proactive (adaptation before impact) and reactive (adaptation after impact) adaptation measures. It was concluded that proactive measures could significantly reduce the economic costs and impacts of climate change when compared to reactive measures. Also, developing countries will encounter relatively higher costs for road networks due to climate change impact through 2100, when compared to developed countries. Schweikert et al. (2015) estimated the impact of climate change on road networks in South Africa. This study also came to a common conclusion that proactive adaptation measures can significantly reduce the annual average cost of road networks in South Africa. A similar study carried out by Melvin et al. (2016) to estimate the economics of proactive adaptation in Alaska, USA, noticed that the largest source of infrastructure damage in Alaska was road flooding. Proactive adaptation for road flooding will reduce the adaptation cost from $\$ 2.3$ billion to $\$ 340$ million. Further, to optimize the maintenance strategy, Qiao et al. (2015) estimated the impact of climate change on various maintenance strategies using MEPDG predictions, and corresponding life cycle cost was also computed. The authors concluded that the maintenance might trigger much earlier than expected. Further, adapting to early maintenance will result in minimizing the total life cycle cost of pavements. Also, maintenance intervention optimization by reducing the total life cycle cost will improve the resilience of pavement infrastructure against climate change. However, ignoring the early triggered maintenance may increase the life cycle cost of pavement.

Underwood et al. (2017) estimated the economic costs of a flexible pavement with the use of correct and incorrect asphalt grade for all roadway types. For 2040, the estimated costs across the United States are US $\$ 19.0$ and US $\$ 26.3$ billion for RCP 4.5 and RCP 8.5, respectively. Similarly, for 2070, the estimated costs across the United States are US $\$ 21.8$ and US $\$ 35.8$ billion for RCP 4.5 and RCP 8.5, respectively. This clearly explains selecting the correct grade of asphalt binder plays an essential role in the economic costs of pavement.

\subsection{Life cycle assessment (LCA)}

Valle et al. (2017) carried out LCA for a segment of interstate pavement considering future climate data in pavement performance evaluation and calculated the GWP to compare various pavement structures, rehabilitation alternatives, and rehabilitation trigger thresholds for both historical climate and climate change data. From this study, it was concluded that LCA could provide a good decision process to select the appropriate pavement structure and rehabilitation alternatives for the future climate. Sharma et al. (2020) estimated the early maintenance that was expected due to climate change. Also, frequent maintenance results in additional traffic delay emissions and costs. From this study, it was concluded that the need for early maintenance in El Paso and Austin, Texas, USA, resulted in 70 tonnes of $\mathrm{CO}_{2}$ per day and US $\$ 100000$ per maintenance day. Therefore, it is necessary to carry out the LCA for all the different adaptation strategies to select the optimal adaptation strategy. The road transportation sector is a major source of total human-made GHG emissions. LCCA and LCA methodologies can be combined to optimize the construction and maintenance strategies to maximize serviceability and durability and also to reduce emissions (Qiao et al. 2020a).

\section{Concluding remarks}

This review explores the literature to quantify the impact of climate change on pavement infrastructure. Initially, a brief introduction to climate change models and uncertainties involved in them is given. Various downscaling techniques to resolve climate models into finer grid scales are discussed. To assess the impact of climate change on pavement performance, many studies utilized AASHTOware mechanistic-empirical design and HDM deterioration models. For this estimation, AASHTOware takes in hourly climate data as input. Therefore, to convert the daily data from downscaled GCMs to hourly values, four hourly data estimation methods are described. Various evidence demonstrating that climate change accelerates pavement deterioration, leading to reduced service life, is illustrated in this study. To uphold the design service life, adaptation strategies such as upgrading asphalt binder grade, change in design thickness, and early triggered maintenance and rehabilitation techniques are discussed. Also, LCCA and LCA analyses of these adaptation strategies are exhibited. The conclusions drawn from this study are as follows:

1. From various studies, it has been noted that temperature is one of the predominant factors that affects pavement deterioration. An increase in temperature due to climate change will result in a shift in asphalt binder grade. In addition, temperature rise can alter the $E^{*}$ value of the surface HMA layer, which leads to a reduction in the service life of the pavement.

2. Precipitation is also a vital climate factor that affects pavement deterioration. An increase in precipitation causes moisture imbalance in the subgrade, which results in the reduction of subgrade stiffness properties. This reduction in properties leads to increased permanent deformation.

3. Other climate factors responsible for pavement deterioration are percent sunshine, wind speed, humidity, and groundwater level; however, the effect of these climate factors may or may not be significant, depending on the climatic zone or location.

4. The increase in percent sunshine is likely to affect the asphalt materials through asphalt aging, embrittlement, and cracking, which results in increased thermal cracking and fatigue cracking. However, the temperature rise may reduce the thermal cracking in pavements.

5. The pavement roughness can be impacted by changing climate either negatively or positively, depending on the location, climatic zone, or environmental variables; however, the impact is noted to be not significant.

6. Rise in temperature and groundwater levels reduce the pavement service life, especially in coastal regions. Therefore, an increase in HMA layer thickness might be a good adaptation strategy for temperature rise. Besides, stabilizing base layers will result in a resilient pavement against rising groundwater levels.

7. Changing climate will trigger the early maintenance of pavements, as is evident in most of the studies considered. 
8. Adapting to future climate increases the economic cost of pavement; however, proactive adaptation has been less burdensome on the life cycle cost than reactive adaptation strategies.

9. LCA can provide a good decision process to select the appropriate pavement structure and rehabilitation alternative for the future climate.

\section{Future work}

Although many studies quantify the impact of climate change on pavement materials, design, performance, maintenance, and rehabilitation, there is a necessity to enhance the accuracy of estimations. Similarly, the adaptation and mitigation strategies need to be optimized for climate change impact. Accordingly, some recommendations for future work are summarized as follows:

1. Most of the studies relied on a single climate model to estimate climate change effects on pavement infrastructure. This estimation can lead to overestimation or underestimation. So, there is a necessity to consider a range of climate models and report the mean or median of the comprehensive set based on statistical distributions.

2. From the literature, it was noted that there is uncertainty involved with climate change models. Therefore, selecting a bias-corrected, statistically downscaled climate model will result in less uncertainty.

3. Temperature and precipitation are the two significant factors that affect pavement materials and design. Although the other climate factors are less significant, there is an indirect effect on the pavement deterioration. Therefore, it is necessary to estimate the individual contributions of all other climate variables on pavement deterioration.

4. Future traffic is another factor that significantly affects pavement infrastructure. It is also necessary to estimate the impact of the interaction effect of climate factors and future traffic on the pavement service life.

5. Temperature rise due to climate change is the primary concern for asphalt concrete pavements. Many studies suggested adaptation and mitigation strategies such as asphalt binder upgrade, increasing HMA layer thickness, and using modified HMA. However, it is necessary to examine the cost-effectiveness of these adaptation and mitigation strategies.

6. Several researchers suggested various adaptation strategies to counteract climate change impact; however, it is necessary to evaluate the LCCA and LCA of all the adaptation strategies to select the sustainable adaptation and mitigation strategy.

\section{Contributors' statement}

The authors confirm contribution to the paper as follows: study conception and design: Surya Swarna, Kamal Hossain; article collection: Surya Swarna, Kamal Hossain; critique the literature: Surya Swarna, Kamal Hossain; draft manuscript preparation: Surya Swarna; manuscript review: Surya Swarna, Kamal Hossain. All authors reviewed the results and approved the final version of the manuscript.

\section{Data availability statement}

No data, models, or code were generated or used during the study.

\section{References}

Achebe, J., Oyediji, O., Saari, R.K., Tighe, S., and Nasir, F. 2021. Incorporating flood hazards into pavement sustainability assessment. Transportation Research Record: Journal of the Transportation Research Board, 2675: 10251042. doi:10.1177/03611981211014525.
ARA Inc. 2004. Guide for mechanistic-empirical design of new and rehabilitated pavement structures, final report. NCHRP Project 1-37A. National Cooperative Highway Research Program (NCHRP), Transportation Research Board, National Research Council, Washington, DC.

Asadi, M., Nazarian, S., Mallick, R.B., and Tirado, C. 2020. Computational process for quantifying the impact of flooding on remaining life of flexible pavement structures. Journal of Transportation Engineering, Part B: Pavements, 146(4): 04020060. doi:10.1061/jpeodx.0000219.

Basit, A., Shafiee, M., Bashir, R., and Perras, M.A. 2021. Climate change implications for asphalt binder selection in pavement. In Proceedings of the International Conference on Transportation and Development 2021, Virtual conference, 8-10 June 2021. Edited by C.R. Bhat. American Society of Civil Engineers, Reston, Va. pp. 289-300.

Belcher, S.E., Hacker, J.N., and Powell, D.S. 2005. Constructing design weather data for future climates. Building Services Engineering Research and Technology, 26(1): 49-61. doi:10.1191/0143624405bt112oa.

Benjamin, D.M., and Budescu, D.V. 2018. The role of type and source of uncertainty on the processing of climate models projections. Frontiers in Psychology, 9: 403. doi:10.3389/fpsyg.2018.00403. PMID:29636717.

Bizjak, K.F., Dawson, A., Hoff, I., Makkonen, L., Ylhaisi, J.S., and Carrera, A. 2014. The impact of climate change on the European road network. Proceedings of the Institution of Civil Engineers - Transport, 167(5): 281-295. doi:10.1680/tran. 11.00072.

Camici, S., Brocca, L., Melone, F., and Moramarco, T. 2014. Impact of climate change on flood frequency using different climate models and downscaling approaches. Journal of Hydrologic Engineering, ASCE, 19(8): 04014002. doi:10. 1061/(ASCE)HE.1943-5584.0000959.

Chai, G., and Kelly, G. 2014. The impacts of climate change on pavement maintenance in Queensland, Australia. In TRA2014: Proceedings of the 5th Conference: Transport Solutions from Research to Deployment Innovate Mobility, Mobilise Innovation!, Paris, France, 14-17 April 2014. Transport Research Arena (TRA)

Chen, X., and Wang, H. 2020. Quantification of warming temperature impact on flexible pavement overlay performance in New Jersey. In TRB Annual Meeting 2020: Proceedings of the 99th Annual Meeting, Washington, DC, 12-16 January 2020. Transportation Research Board (TRB), The National Academies of Sciences, Engineering, and Medicine, Washington, DC.

Chow, D.H.C., and Levermore, G.J. 2007. New algorithm for generating hourly temperature values using daily maximum, minimum and average values from climate models. Building Services Engineering Research and Technology, 28(3): 237-248. doi:10.1177/0143624407078642.

Dash, S.K., Jenamani, R.K., Kalsi, S.R., and Panda, S.K. 2007. Some evidence of climate change in twentieth-century India. Climatic Change, 85(3-4): 299-321. doi:10.1007/s10584-007-9305-9.

Delgadillo, R., Arteaga, L., Wahr, C., and Alcafuz, R. 2020. The influence of climate change in Superpave binder selection for Chile. Road Materials and Pavement Design, 21(3): 607-622. doi:10.1080/14680629.2018.1509803.

Evans, J.P. 2009. 21st century climate change in the Middle East. Climatic Change, 92(3-4): 417-432. doi:10.1007/s10584-008-9438-5.

Finnis, J., and Daraio, J. 2018. Projected impacts of climate change for the province of Newfoundland \& Labrador: 2018 update. Memorial University of Newfoundland, St. John's, Nfld. 198 pp.

Flato, G., Marotzke, J., Abiodun, B., Braconnot, P., Chou, S.C., Collins, W., et al. 2013. Evaluation of climate models. In Climate Change 2013: The Physical Science Basis. Edited by T.F. Stocker, D. Qin, G.-K. Plattner, M. Tignor, S.K. Allen, J. Boschung, et al. Contribution of Working Group I to the Fifth Assessment Report of the Intergovernmental Panel on Climate Change. Cambridge University Press, Cambridge, UK and New York, NY. pp. 741-866

Fletcher, C.G., Matthews, L., Andrey, J., and Saunders, A. 2016. Projected changes in mid-twenty-first-century extreme maximum pavement temperature in Canada. Journal of Applied Meteorology and Climatology, 55(4): 961974. doi:10.1175/JAMC-D-15-0232.1.

Gasparrini, A., Guo, Y., Sera, F., Vicedo-Cabrera, A.M., Huber, V., Tong, S., et al. 2017. Projections of temperature-related excess mortality under climate change scenarios. The Lancet Planetary Health, 1(9): e360-e367. doi:10.1016| S2542-5196(17)30156-0.

Gudipudi, P.P., Underwood, B.S., and Zalghout, A. 2017. Impact of climate change on pavement structural performance in the United States. Transportation Research Part D: Transport and Environment, 57: 172-184. doi:10.1016/ j.trd.2017.09.022

Hughes, L. 2003. Climate change and Australia: trends, projections and impacts. Austral Ecology, 28(4): 423-443. doi:10.1046/j.1442-9993.2003.01300.x.

IPCC. 2007. Climate change 2007: synthesis report. Contribution of working groups I, II and III to the fourth assessment report of the intergovernmental panel on climate change. Edited by Core Writing Team, R.K. Pachauri, and A. Reisinger. Intergovernmental Panel on Climate Change (IPCC), Geneva, Switzerland. 104 pp.

Jeong, H., Kim, H., Kim, K., and Kim, H. 2017. Prediction of flexible pavement deterioration in relation to climate change using fuzzy logic. Journal of Infrastructure Systems, ASCE, 23(4): 04017008. doi:10.1061/(ASCE) IS.1943-555X.0000363.

Jones, P.G., and Thornton, P.K. 2009. Croppers to livestock keepers: livelihood transitions to 2050 in Africa due to climate change. Environmental Science and Policy, 12(4): 427-437. doi:10.1016/j.envsci.2008.08.006. 
Knott, J.F., Jacobs, J.M., Sias, J.E., Kirshen, P., and Dave, E.V. 2019a. A framework for introducing climate-change adaptation in pavement management. Sustainability, 11(1): 4382, doi:10.3390/su11164382.

Knott, J.F., Sias, J.E., Dave, E.V., and Jacobs, J.M. 2019b. Seasonal and long-term changes to pavement life caused by rising temperatures from climate change. Transportation Research Record, 2673(6): 267-278. doi:10.1177/0361198119844249.

Knott, J.F., Sias, J.E., Jacobs, J.M., Krishen, P., and Dave, E.V. 2020. Designing a climate-ready coastal road. In Proceedings of the TRB 99th Annual Meeting, Walter E. Washington Convention Center, Washington, DC, 1216 January 2020. Transportation Research Board (TRB), Washington DC.

Kudo, R., Yoshida, T., and Masumoto, T. 2017. Uncertainty analysis of impacts of climate change on snow processes: case study of interactions of GCM uncertainty and an impact model. Journal of Hydrology, 548: 196-207. doi:10.1016/j.jhydrol.2017.03.007.

Kumlai, S., Jitsangiam, P., and Pichayapan, P. 2017. The implications of increasing temperature due to climate change for asphalt concrete performance and pavement design. KSCE Journal of Civil Engineering, 21(4): 1222-1234. doi:10.1007/s12205-016-1080-6.

Kundzewicz, Z.W., Krysanova, V., Benestad, R.E., Hov, Ø., Piniewski, M., and Otto, I.M. 2018. Uncertainty in climate change impacts on water resources. Environmental Science \& Policy, 79: 1-8. doi:10.1016/j.envsci.2017.10.008.

Lioubimtseva, E., and Henebry, G.M. 2009. Climate and environmental change in arid Central Asia: impacts, vulnerability, and adaptations. Journal of Arid Environments, 73(11): 963-977. doi:10.1016/j.jaridenv.2009.04.022.

Maadani, O., Shafiee, M., and Egorov, I. 2021. Climate change challenges for flexible pavement in Canada: an overview. Journal of Cold Regions Engineering, 35(4): 03121002. doi:10.1061/(ASCE)CR.1943-5495.0000262.

Mallick, R., Radzicki, M., Daniel, J., and Jacobs, J. 2014. Use of system dynamics to understand long-term impact of climate change on pavement performance and maintenance cost. Transportation Research Record, 2455: 1-9. doi:10.3141/2455-01.

Mallick, R., Jacobs, J.M., Miller, B.J., Daniel, J.S., Mallick, R.B., Jacobs, J.M., et al. 2016. Understanding the impact of climate change on pavements with CMIP5, system dynamics and simulation. International Journal of Pavement Engineering, 19: 697-705. doi:10.1080/10298436.2016.1199880.

Mallick, R.B., Tao, M., Daniel, J.S., Jacobs, J., and Veeraragavan, A. 2017. Development of a methodology and a tool for the assessment of vulnerability of roadways to flood-induced damage. Journal of Flood Risk Management, 10(3): 301-313. doi:10.1111/jfr3.12135.

Marengo, J.A., Chou, S.C., Kay, G., Alves, L.M., Pesquero, J.F., Soares, W.R., et al. 2012. Development of regional future climate change scenarios in South America using the Eta CPTEC/HadCM3 climate change projections: climatology and regional analyses for the Amazon, São Francisco and the Paraná River basins. Climate Dynamics, 38(9-10): 1829-1848. doi:10.1007| s00382-011-1155-5.

Mauritzen, C., Zivkovic, T., and Veldore, V. 2017. On the relationship between climate sensitivity and modelling uncertainty. Tellus A: Dynamic Meteorology and Oceanography, 69(1): 1327765. doi:10.1080/16000870.2017.1327765.

Meagher, W., Daniel, J.S., Jacobs, J., and Linder, E. 2012. Method for evaluating implications of climate change for design and performance of flexible pavements. Transportation Research Record, 2305: 111-120. doi:10.3141/2305-12.

Meinshausen, M., Smith, S.J., Calvin, K., Daniel, J.S., Kainuma, M.L.T., Lamarque, J., et al. 2011. The RCP greenhouse gas concentrations and their extensions from 1765 to 2300. Climatic Change, 109(1): 213-241. doi:10.1007| s10584-011-0156-z.

Meleux, F., Solmon, F., and Giorgi, F. 2007. Increase in summer European ozone amounts due to climate change. Atmospheric Environment, 41(35): 7577-7587. doi:10.1016/j.atmosenv.2007.05.048.

Melvin, A.M., Larsen, P., Boehlert, B., Neumann, J.E., Chinowsky, P., and Espinet, X. 2016. Climate change damages to Alaska public infrastructure and the economics of proactive adaptation. Proceedings of the National Academy of Sciences of the United States of America, 114: E122-E131. doi:10.1073/pnas.1611056113. PMID:28028223.

Mills, B., Tighe, S., Huen, K., and Parm, S. 2006. Climate change and the performance of pavement infrastructure in southern Canada: context and case study. In Proceedings of the 2006 IEEE EIC Climate Change Conference, Ottawa, Ont., 10-12 May 2006. doi:10.1109/EICCCC.2006.277185.

Mills, B., Tighe, S., Andrey, J., Smith, J., and Huen, K. 2009. Climate change implications for flexible pavement design and performance in southern Canada. Journal of Transportation Engineering, ASCE, 135(10): 773-782. doi:10.1061/(ASCE)0733-947X(2009)135:10(773).

Murphy, J. 1999. An evaluation of statistical and dynamical techniques for downscaling local climate. Journal of Climate, 12: 2256-2284. doi:10.1175/ 1520-0442(1999)012<2256:AEOSAD > 2.0.CO;2.

Paquin, D., De Elía, R., and Frigon, A. 2014. Change in North American atmospheric conditions associated with deep convection and severe weather using CRCM4 climate projections. Atmosphere-Ocean, 52(3): 175-190. doi:10.1080/ 07055900.2013.877868.

Qiao, Y., Dawson, A., Parry, T., and Flintsch, G. 2013a. Quantifying the effect of climate change on the deterioration of a flexible pavement. In Proceedings of the 9th International Conference on the Bearing Capacity of Roads, Railways and Airfields, Trondheim, Norway, 25-27 June 2013. Edited by I. Hoff, H. Mork, and R.G. Saba. Norwegian University of Science and Technology. pp. 555-563.
Qiao, Y., Flintsch, G., Dawson, A., and Parry, T. 2013b. Examining effects of climatic factors on flexible pavement performance and service Life. Transportation Research Record: Journal of the Transportation Research Board, 2349(1): 100-107. doi:10.3141/2349-12.

Qiao, Y., Dawson, A.R., Parry, T., and Flintsch, G.W. 2015. Evaluating the effects of climate change on road maintenance intervention strategies and Life-Cycle Costs. Transportation Research Part D: Transport and Environment, 41: 492-503. doi:10.1016/j.trd.2015.09.019.

Qiao, Y., Casey, D.B., Kuna, K.K., Kelly, K., and Macgregor, I.D. 2016. Climate resilience of flexible pavement highways: assessment of current practice. In Proceedings of the LJMU Annual International Conference on Asphalt, Pavement Engineering and Infrastructure, Liverpool, UK, 24-25 February 2016. Liverpool John Moores University (LJMU). pp. 1-14.

Qiao, Y., Santos, J., Stoner, A.M.K., and Flinstch, G. 2020a. Climate change impacts on asphalt road pavement construction and maintenance: an economic life cycle assessment of adaptation measures in the State of Virginia, United States. Journal of Industrial Ecology, 24: 342-355. doi:10.1111/ jiec.12936.

Qiao, Y., Dawson, A.R., Parry, T., Flintsch, G., and Wang, W. 2020b. Flexible pavements and climate change: a comprehensive review and implications. Sustainability, 12(3): 1057. doi:10.3390/su12031057.

Rana, M., Swarna, S., and Hossain, K. 2020. Climate change impact on pavement performance in Newfoundland, Canada. In Proceedings of TRB 99th Annual Meeting, Washington, DC, 12-16 January 2020. Transportation Research Board, Washington, DC.

Schweikert, A., Chinowsky, P., Espinet, X., and Tarbert, M. 2014. Climate change and infrastructure impacts: comparing the impact on roads in ten countries through 2100. Procedia Engineering, 78: 306-316. doi:10.1016/j.proeng.2014. 07.072 .

Schweikert, A., Chinowsky, P., Kwiatkowski, K., Johnson, A., Shilling, E., Strzepek, K., and Strzepek, N. 2015. Road infrastructure and climate change: impacts and adaptations for South Africa. Journal of Infrastructure Systems, ASCE, 21(3): 04014046. doi:10.1061/(ASCE)IS.1943-555X.0000235.

Shafiee, M., Maadani, O., Murphy, E., and Canada, C. 2020. Climate change and asphalt binder selection: resilient roads of the future. In Proceedings of the 2020 TAC Conference \& Exhibition, 21 September-8 October 2020. Transportation Association of Canada (TAC), Ottawa, Ont

Shao, Z., Jenkins, G., and Oh, E. 2017. Assessing the impacts of climate change on road infrastructure. International Journal of GEOMATE, 13(38): 120-128. doi:10.21660/2017.38.72099.

Sharma, M., Inti, S., Tandon, V., and Byreddy, H. 2020. Economical and environmental impact of climate change on Texas pavements. In Proceedings of the TRB 99th Annual Meeting, Walter E. Washington Convention Center, Washington, DC, 12-16 January 2020. Transportation Research Board (TRB), Washington DC.

Stocker, T.F., Qin, D., Plattner, G.-K., Tignor, M., Allen, S.K., Boschung, J., et al. (Editors). 2013. Climate change 2013: the physical science basis. Contribution of working group I to the fifth assessment report of the intergovernmental panel on climate change. Cambridge University Press, Cambridge, UK and New York, NY. 1535 pp.

Stoner, A.M.K., Daniel, J.S., Jacobs, J.M., Hayhoe, K., and Scott-Fleming, I. 2019. Quantifying the impact of climate change on flexible pavement performance and lifetime in the United States. Transportation Research Record, 2673(1): 110-122. doi:10.1177/0361198118821877.

Swarna, S., and Hossain, K. 2018. Effect of interface bonds on pavement performance. In Proceedings of the 2018 TAC Conference, Saskatoon, Sask. Transportation Association of Canada (TAC), Ottawa, Ont.

Swarna, S.T, Hossain, K., Pandya, H., and Mehta, Y.A. 2021. Assessing climate change impact on asphalt binder grade selection and its implications. Transportation Research Record, 2675(10): 786-799. doi:10.1177/03611981211013026.

Taylor, K.E., Stouffer, R.J., and Meehl, G.A. 2012. An overview of CMIP5 and the experiment design. Bulletin of the American Meteorological Society, 93(4): 485-498. doi:10.1175/BAMS-D-11-00094.1.

Tighe, S., Mills, B., Tighe, S.L., Smith, J., Mills, B., and Andrey, J. 2008. Evaluating climate change impact on low-volume roads in southern Canada. Transportation Research Record, 2053(1): 9-16. doi:10.3141/2053-02.

Underwood, S. 2021. A method to select general circulation models for pavement performance evaluation. International Journal of Pavement Engineering, 22(2): 134-146. doi:10.1080/10298436.2019.1580365.

Underwood, S., Guido, Z., Gudipudi, P., and Feinberg, Y. 2017. Increased costs to US pavement infrastructure from future temperature rise. Nature Climate Change, 7: 704-707. doi:10.1038/nclimate3390.

Valle, O., Qiao, Y., Dave, E., and Mo, W. 2017. Life cycle assessment of pavements under a changing climate. In Proceedings of the Symposium on Life-Cycle Assessment of Pavements (Pavement LCA 2017), Champaign, Ill., 12-13 April 2017. 1st ed. Edited by I.L. Al-Qadi, H. Ozer, and J. Harvey. CRC Press, London, UK. pp. 241-250.

Vincent, L.A., Zhang, X., Mekis, É., Wan, H., and Bush, E.J. 2018. Changes in Canada's climate: trends in indices based on daily temperature and precipitation data. Atmosphere-Ocean, 56(5): 332-349. doi:10.1080/07055900. 2018.1514579.

Viola, F., and Celauro, C. 2015. Effect of climate change on asphalt binder selection for road construction in Italy. Transportation Research Part D: Transport and Environment, 37: 40-47. doi:10.1016/j.trd.2015.04.012. 
Wang, J., Fonseca, R.M., Rutledge, K., Martín-Torres, J., and Yu, J. 2019. Weather simulation uncertainty estimation using Bayesian hierarchical models. Journal of Applied Meteorology and Climatology, 58(3): 585-603. doi:10.1175/ JAMC-D-18-0018.1.

Wistuba, M.P., and Walther, A. 2013. Consideration of climate change in the mechanistic pavement design. Road Materials and Pavement Design, 14: 227-241. doi:10.1080/14680629.2013.774759.

Wood, A.W., Leung, L.R., Sridhar, V., and Lettenmaier, D.P. 2004. Hydrologic implications of dynamical and statistical approaches to downscaling climate model outputs. Climatic Change, 62(1): 189-216. doi:10.1023/B: CLIM.0000013685.99609.9e.
Zapata, C.E., Andrei, D., Witczak, M.W., and Houston, W.N. 2007. Incorporation of environmental effects in pavement design. Road Materials and Pavement Design, 8(4): 667-693. doi:10.1080/14680629.2007.9690094.

Zareie, A., Amin, S.R., and Amador-Jiménez, L. 2016. Thornthwaite moisture index modeling to estimate the implication of climate change on pavement deterioration. Journal of Transportation Engineering, ASCE, 142(4): 04016007. doi:10.1061/(ASCE)TE.1943-5436.0000840.

Zhai, P., and Pan, X. 2003. Trends in temperature extremes during 19511999 in China. Geophysical Research Letters, 30(17): 1913. doi:10.1029/ 2003 GL018004. 